\section{Nobel laureates know what they're talking about}

\section{SIR - Your Editorial 'Nobels in dubious} causes' (Nature 447, 354; 2007) urges scientists and Nobel laureates to "campaign only where they can truly make a difference". I think you mean that we should use our fleeting fame only in causes that we know something about. Or, as Pliny the Elder put it: "Shoemaker, stick to your last".

A few laureates may sign too many things. However, as a founder and board member of Scientists and Engineers for America, I use my Nobel prize to discuss something I know a good deal about.

Our aim is to make available to society at large the evidence-based science relating to critical issues facing us all. There is a lot of shouting out there and it is hard for the layperson to find reality. Political affiliation does not matter to us. Both Republican and Democratic presidential candidates endorse corn-based ethanol as an energy source. Both are wrong; it is our job to call it mainly a farm subsidy and explain why it is that rather than what it is claimed to be. It is up to the public to decide how much to support it.

We are also educating scientists on how to run for school boards. We hope many of them will win, and in this way improve the poor state of science education in our schools and keep it focused on the real world.

We intend to inform the electorate of the science-based issues that their elected officials have to face, and of what actions these officials have taken. We also intend to summarize the science behind the issues, including what we know and what we don't know. We hope both to draw attention to under-appreciated science issues and provide the advocacy necessary to get things done - not along party-political lines, but scientifically.

\section{Burton Richter}

Stanford University, SLAC MS 80, 2575 Sand Hill

Road, Menlo Park, California 94025, USA

\section{Nobel: politicians need the insights scientists can give}

SIR - As a member of the board of directors for Scientists and Engineers for America (SEA) and president of the Federation of American Scientists, two organizations mentioned in your Editorial 'Nobels in dubious causes' (Nature 447, 354; 2007), I must take exception to your argument that scientists should not overstep their expertise.

In matters of interior decoration you'd be as likely to get good advice from a person pulled at random off the streets of Glasgow as from a gaggle of Nobel laureates. But eminent scientists bring much-needed perspectives and insight to policy decisions that hinge on scientific facts and methods, and the uncertainties associated with them. Many of the most difficult political issues today such as climate change, securing nuclear materials, setting priorities in health research and many others - are intimately tied to issues in science.

Given the cacophony of biased and misleading information that dominates many of these debates, the kind of advice and leadership provided by scientists is essential.

How could it be considered 'dubious' for scientists to defend and explain the process of scientific inquiry, when elected officials are making technical decisions based on the advice of novelists and religious extremists? SEA was organized to ensure that candidates positions on critical science-policy matters are easily available, clearly understood and openly debated.

Your Editorial implies that this essential public service is inappropriate. On the contrary, it would be a terrible mistake if scientists with information critical to the debate retreat to ivory towers. Scientists have a responsibility to bring relevant facts to light, provide early warnings of problems that scientists are uniquely able to see and suggest solutions that might otherwise not enter the debate.

Henry Kelly

Scientists and Engineers for America,

Federation of American Scientists, Suite 209,

1717 K Street NW, Washington DC 20036, USA

\section{How a naturalist found safe colours for soldiers}

SIR - I enjoyed the Science in Culture article 'Hidden talent' about the London exhibition exploring the art of camouflage and its military implications (Nature 447, 148; 2007). It reminded me of a little-known Englishman who made contributions to both zoology and military camouflage.

Charles Hamilton Smith (1776-1859), a colonel in the British Army, was a naturalist who described several equine species and subspecies - now mostly synonymized with Equus - and wrote an important volume in William Jardine's Naturalist's Library series (The Natural History of Horses Lizars, Edinburgh, 1841). Charles Darwin cited this work in his Origin of Species, in connection with hybridism and equine striping patterns.

Hamilton Smith is also known to military historians for his experiment conducted in 1800 on the colour of soldiers' field uniforms. The experiment involved soldiers firing at targets of different colours, including the conspicuous red of the British soldier's field uniform. This colour was more than twice as likely as grey to receive a bullet-hole. Hamilton Smith submitted a report concluding that "the question arises whether all riflemen and light infantry should not take the field in some grey unostentatious uniform, leaving the parade dress for peace and garrison duty" (published later in the Royal Engineers' Aide Memoire to the Military Sciences, Weale, London, 1853).

Although some sections of the army readily took up Hamilton Smith's recommendations, cryptic coloration in British field uniforms was not fully adopted until the Boer War, at the end of the nineteenth century. Hamilton Smith was born in the year of the US declaration of independence; had someone conducted his experiment before that time - and had the British authorities been more willing to respond - history might have taken a rather different turn.

James T. Costa

Highlands Biological Station, 265 N. Sixth Street, Highlands, North Carolina 28741, USA and Department of Biology, Western Carolina University, Cullowhee, North Carolina 28723, USA

\section{Post-publication review could aid skills and quality}

SIR - Shi V. Liu's correspondence, 'Why are people reluctant to join in open review?' (Nature 447, 1052; 2007), struck a chord. Recently, I stayed my hand before submitting a comment to an online article, because the comment included as-yet unpublished research that I was reluctant to reveal in such a forum.

I believe that there are two ways to encourage online commenting. These would require little additional commitment, but would improve journal quality and enhance the development of review skills among young scientists.

First, journals could institute periodic post-publication review, in which the journal would solicit formal review of the article, focusing on how well its methods and results have held up, given the research that has been published in the intervening period. Such reviews would provide valuable historical perspective. Second, young scientists participating in journal clubs could be asked to derive and post a consensus comment on the article under discussion.

Todd A. Gibson

University of Colorado at Denver and Health Sciences Center, PO Box 6511, Mail Stop 8303, Aurora, Colorado 80045, USA

\section{Correction}

PLoS One published just over 550 articles during its first six months, not 1,189 as stated in Correspondence 'Why are people reluctant to join in open review?' (Nature 447, 1052; 2007). 